\title{
Residual biomass potential of commercial and pre-commercial sugarcane cultivars
}

\author{
Marcos Guimarães de Andrade Landell ${ }^{*}$, Maximiliano Salles Scarpari ${ }^{1}$, Mauro Alexandre Xavier ${ }^{1}$, Ivan Antônio dos Anjos ${ }^{1}$, Antônio

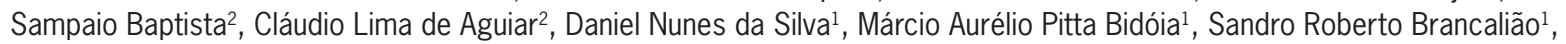 \\ José Antônio Bressiani ${ }^{3}$, Marcelo Ferraz de Campos $^{1}$, Paulo Eduardo Martins Miguel ${ }^{1}$, Thiago Nogueira da Silva ${ }^{1}$, Victor Hugo \\ Pavelqueires da Silva ${ }^{1}$, Luciana Oliveira Souza Anjos ${ }^{1}$, Bruna Harumi Ogata ${ }^{2}$
}

${ }^{1}$ AC/Apta - Centro Avançado de Pesquisa Tecnológica do Agronegócio da Cana, Rod. Prefeito Antônio Duarte Nogueira, km 321 C.P. 206 - 14001-970 - Ribeirão Preto, $\mathrm{SP}$ - Brasil.

USP/ESALQ - Depto. de Agroindústria, Alimentos e Nutrição, Av. Pádua Dias, 11 - 13418-900 - Piracicaba, $\mathrm{SP}$ - Brasil.

${ }^{3}$ GraalBio, Av. Brigadeiro Faria Lima, 2277, cj. 1501 -

01452-000 - São Paulo, SP - Brasil.

${ }^{*}$ Corresponding author <mlandell@iac.sp.gov.br>

Edited by: Paulo Sergio Graziano Magalhães

\begin{abstract}
Sugarcane (Saccharum spp.) is an efficient and sustainable alternative for energy generation compared to non-renewable sources. Currently, during the mechanized harvest process, the straw left in the field can be used in part for the second generation ethanol and increasing the electric energy production. Thus, this study aimed to provide information on the potential for residual biomass cultivars of sugarcane cropping system. This study provides the following information: yield of straw, depending on the calculated leaf area index and the number of tillers per linear meter; primary energy production of several sugarcane genotypes; contribution of dry tops and leaves; biomass yield; and evaluation of fiber, cellulose, hemicellulose and lignin. Preliminary results obtained by researchers of the State of São Paulo, Brazil, and reCviews related studies are presented. The results suggest that the production of sugarcane straw content varies according to the cultivars; the greater mass of sugarcane straw is in the top leaves and that the potential for the crude energy production of sugarcane per area unit can be increased using fiber-rich species or species that produce more straw. The straw indexes was shown to be a good indicator and allow the estimation of straw volumes generated in a sugarcane crop. The cellulose, hemicellulose and lignin composition in sugarcane is distinct among varieties. Therefore, it is possible to develop distinct biomass materials for energy production and for the development of sugarcane mills using biochemical processes and thermal routes.

Keywords: straw, genotypes, composition
\end{abstract}

\section{Sugarcane straw and cultivars}

The mechanized harvesting process for sugarcane (Saccharum spp.) generates significant dry mass deposition on the soil during cropping. Among the several uses of this residue are energy co-generation and raw material for ethanol and biochemical production. It is still unknown the amount of residual straw that should be removed from the soil surface to be used in energy generation and how much should remain for soil conservation, given the benefits it brings to tropical soils and sugarcane cropping.

The straw mass generated is directly related to the sugarcane crop yield, which varies according to the cultivar, environment and management system adopted. The straw mass generated is an intrinsic characteristic of a cultivar and ranges from 8 to $23 \%$ of the stem weight (Franco et al., 2013) and $14 \%$ of the dry weight (Paes and Oliveira, 2005). It is crucial to determine the amount of residual dry mass that should remain on the soil and the amount that can be removed after harvest.

This study aimed to provide information about the residual biomass potential of specific sugarcane cultivars under a mechanized harvesting unburned system. Part of this information was generated through a series of studies developed within the project: Sustainable Bioenergy Sugarcane Breeding and Cultivar Development (Bioen project - FAPESP).

\section{Straw}

Sugarcane genetic improvement should no longer be based solely on characteristics to increase sugar yield, Sugar Tons per Hectare (STH), but it should be based on biomass production indicated by the fiber mass, Fiber Tons per Hectare; (FTH) that is available for energy and second-generation ethanol production. The STH and FTH composition provides the total biomass or Dry Matter Tons per Hectare (DMTH), where the saccharose-rich syrup constitutes the feedstock for sugar production and the residual fiber (bagasse plus soil surface straw) is the raw material for energy, biochemical and biofuel production. Currently, these new technologies are hindered by the economic costs of biomass use, in other words, cost of sugarcane per ton should not exceed US\$20.00.

In 2031, all sugarcane straw from sugarcane harvest in Brazil will be available for use (Gomes et al., 2010). Harvesting methods for sugarcane straw will be implemented based on the principles and concepts that are compatible with the needs and economic processes, which will, therefore, place sugarcane straw in a prominent position, along with sugarcane bagasse, as a primary biomass sources for second-generation ethanol production.

When identifying which plant characteristics are determinant for the straw content variation of a sug- 
arcane cultivar in accordance with studies performed at the Centro de Cana/IAC - Instituto Agronômico de Campinas (Sugarcane Center/IAC), we found that leaf area (leaf length) and leaf width are the most important. These characteristics are described in sugarcane botanical studies by the National Service for Cultivar Protection of the Ministry for Agriculture, Livestock and Supply (MAPA) in Brazil regarding leaf width and foliar canopy volume. Leaf length (L) and leaf width (W) comprise the leaf area (LA) and can be expressed as follows: LA = L W 0.75 (Francis et al., 1969). Considering $1.4 \mathrm{~m}$ of length and $0.045 \mathrm{~m}$ of width (standard leaf) (Table 1), the LA per leaf would be $0.047 \mathrm{~m}^{2}$. Considering 13 tillers per linear meter and 16 internodes representing 16 potential leaves, approximately 1.4 million leaves in one hectare would be obtained, which means that $66 \mathrm{~m}^{2} \mathrm{LA}$ and 6.6 leaf layers would cover the entire hectare. The sheaths and top leaves not included in these figures should also be considered. Effectively, these results represent a highly productive commercial crop area with numbers greater than $30 \mathrm{t}$ $\mathrm{ha}^{-1}$.

Miocque (1999) investigated sugarcane growth and biomass for ten crops in São Paulo State (Brazil) and concluded that the period of highest biomass accumulation is between the months of December and February, when sugarcane shows increased growth. Miocque (1999) also reported that sugarcane top leaves account for $26 \%$ of the stem weight at harvest. Thus, after dehydration, the top leaf dry mass in a crop of $100 \mathrm{t} \mathrm{ha}^{-1}$, for example, would be approximately $8 \mathrm{t} \mathrm{ha}^{-1}$.

Table 1 - Leaf area index (LA), leaf $(+3)$ calculated as a function of leaf length $(L)$ and leaf width (W), of sugarcane.

\begin{tabular}{lcccc}
\hline $\begin{array}{l}\text { Leaf length - } \mathrm{L} \\
(\mathrm{m})\end{array}$ & \multicolumn{4}{c}{$\begin{array}{c}\text { Leaf Width - W } \\
(\mathrm{m})\end{array}$} \\
\hline & 0.015 & 0.030 & 0.045 & 0.060 \\
\hline .80 & 0.0090 & 0.0180 & 0.0270 & 0.0360 \\
1.10 & 0.0124 & 0.0247 & 0.0371 & 0.0495 \\
1.40 & 0.0157 & 0.0315 & 0.0472 & 0.0630 \\
1.70 & 0.0191 & 0.0382 & 0.0574 & 0.0765 \\
2.00 & 0.0225 & 0.0450 & 0.0675 & 0.0900 \\
\hline
\end{tabular}

Source: Francis et al. (1969).

\section{Cultivars}

The mechanized sugarcane harvesting system, which prevails in Brazilian crops over crop burning, at first left producers concerned because the high volume of remaining straw on the soil hindered plant sprouting primarily in low-temperature regions, such as the southwestern states of São Paulo, Paraná and Mato Grosso do Sul. This hindrance occurred because the cultivars used at that time had not been developed for mechanized harvesting. In recent years, new cultivars have been developed, studied and used in this new environmental context. Therefore, these new cultivars are better adapted with increased sprouting capacity under the residual straw.

The sprouting difficulty of certain cultivars is less significant in high-temperature regions, such as centralwestern Brazil (Salton et al., 2008). The reduction of light incidence together with temperature reduction and the temperature range in the soil can cause disease proliferation and increased presence of pests, which may decrease crop yield (Ripoli et al., 2005). On the other hand, straw plays an essential role in increasing organic matter and provides benefits regarding water retention and water loss to the atmosphere (Bayer et al., 2002). This aspect shows that distinct criteria are used to define the amount of straw that should be removed for energy production when considering regions with lower or higher temperatures, such as central-western Brazil, where there is a higher hydric deficit (Salton et al., 2008).

After 2007, the Sugarcane Program/IAC ("Programa Cana/IAC") started to investigate new sugarcane cultivars, not only for their capacity to produce sugar, but also for their potential for primary energy production. This parameter accounts for all of the energy that can be produced from sugars and fibers in sugarcane stems and straw, and it was used to characterize the new cultivars at the IAC (Table 2). The primary energy was estimated as follows:

$\mathrm{PE}\left(\mathrm{MJ} \mathrm{t}^{-1}\right)=(18 \times \mathrm{kg}$ Fiber $)+(16 \times \mathrm{kg}$ Saccharose $)+$ [15.6 x RS (kg)]

where: PE is the primary energy expressed in $\mathrm{MJ} \mathrm{t}^{-1}$; Fi-

Table 2 - Production of primary energy of sugarcane cultivars from fiber and total sugars stratification.

\begin{tabular}{lccccc}
\hline Characteristics & IAC91-1099 & IACSP93-2060 & IACSP95-3028 & IACSP95-5000 & RB72454 \\
\hline \% Straw & 17.7 & 8.0 & 10.6 & 15.3 & 12.0 \\
SH $\left(\right.$ t ha $^{-1}$ ) & 115.1 & 104.5 & 96.0 & 115.3 & 110.7 \\
Straw (t ha ${ }^{-1}$ ) & 20.4 & 8.4 & 10.2 & 17.6 & 11.3 \\
Fiber (\%) & 11.4 & 11.2 & 10.9 & 317.6 & 11.1 \\
\hline PE straw & 366.8 & 150.4 & 183.1 & 301.6 & 239.2 \\
PE sugar & 287.1 & 267.0 & 251.4 & 234.6 & 276.1 \\
PE Fiber & 236.3 & 209.6 & 188.1 & 853.9 & 221.2 \\
\hline PE Total & 890.2 & 627.0 & 622.6 & 7.4 & 736.5 \\
\hline PE / t cane (MJ) & 7.7 & 6.0 & 6.5 & & 6.7 \\
\hline
\end{tabular}

SH -Stems per hectare. PE - Primary Energy, expressed in MJ ha ${ }^{-1}$. 
ber is the water insoluble matter in sugarcane expressed as a percentage (Fernandes, 2003).

Saccharose is the main technological sugarcane quality parameter. That sugar is directly crystallized in the production process and is directly related to Pol (apparent saccharose expressed in percentage) in the cane syrup; and RS is the Reduction Sugars, which is a term used to designate the sugars (glucose and fructose) that are capable of reducing copper from a cupric to a cuprous state (Fernandes, 2003).

The primary energy production estimated for IAC91-1099 and IACSP95-5000 was 15\% and 10\% higher than that for RB72454 (Table 2) indicating that the energy yields can be increased by changing sugarcane varieties. Therefore, the initial concerns with the lack of adaptation of some varieties to mechanized harvesting opened the opportunity to investigate the potential use of sugarcane biomass in several sugarcane genotypes.

In a previous study (Manechini, 1997), the type of cultivar was identified as a determinant factor for the volume of straw mass produced, determined by the distinct proportions of leaves (Table 3). Studies performed at the Sugarcane Center/IAC have reported the straw content in several IAC cultivars, with straw percentage values ranging between 9 and $19 \%$ (Table 4). However, Paes and Oliveira (2005) noticed that the straw percentage values in studies by many authors ranged from 2 to $35 \%$ in different productive regions around the world (Table 5). Romero et al. (2007) also noticed a similar trend (Table 6). In other words, that yield levels affect straw content with lower productivity, generally resulting in higher levels of straw content in global biomass production and, therefore, higher straw/TSH ratios (\%).

\section{Relationship among straw, stem straw and top leaves in sugarcane}

In previous studies, we reported values of straw dry mass produced per hectare was for the IACSP933046 (15 t), IAC91-1099 (17 t), IACSP95-5000 (20 t) and IACSP94-2094 (21 t) cultivars. According to Ripoli et al. (2005), the crude energy obtained from straw is approximately $18 \mathrm{MJ} \mathrm{kg}^{-1}$. Therefore, it is estimated that the IACSP94-2094 variety can produce approximately $379 \mathrm{MJ} \mathrm{ha}^{-1}$. Ripoli et al. (2005) quantified straw production and concluded that straw productivity varies as follows: soil surface straw from 1.1 to $2.4 \mathrm{t} \mathrm{ha}^{-1}$; stem straw from 6.5 to $8.4 \mathrm{t} \mathrm{ha}^{-1}$; and top leaves from 6.4 to $11.1 \mathrm{t} \mathrm{ha}^{-1}$ (Figure 1).
We investigated the same materials (Table 7) and observed that there was a ratio that tended to repeat for biomass volumes in top leaves, stem straw, surface soil straw and stem mass within a sugarcane variety. However, these ratios varied according to the variety. The indexes showing the ratio of the Top Leaves Dry Mass (TLDM) to Stem Mass (SM) are between 0.074 and 0.121; therefore, the TLDM accounts for approximately $10 \%$ of the stem mass, which was similar to the observations of Miocque (1999) and Franco et al. (2013). The Stem Straw Dry Mass (SSDM) ratio to SM ranged from 0.071 to 0.094 . Thus, on average, the Stem Straw Dry Mass (SSDM) accounted for approximately $9 \%$ of the SM. Given that the Soil Straw Dry Mass (SoSDM) represented approximately $2 \%$ of the sugarcane SM, the ratios for the sugarcane Total Mass of Sugarcane Dry Straw (TMSDS/SM) ranged from 0.174 to 0.239 .

Technically, it is important to leave part of the straw on the soil. Based on the ratios presented, sugarcane stem straw, which can be collected during mechanized harvesting, accounted for approximately $42 \%$ of the crop total straw. Some sugarcane varieties show spontaneous defoliation, which should be considered when adopting a strategy for crop management. Spontaneous defoliation was observed (Table 7), mainly for the IACSP94-2094 cultivar, which presented a SoSDM/ SM ratio of only $1 \%$.

When soil surface straw is collected, large amounts of minerals are also removed. Therefore, it is recommended to leave surface straw on the soil. Despite being more abundant and accounting for approximately $49 \%$ of the total straw mass, top leaf straw

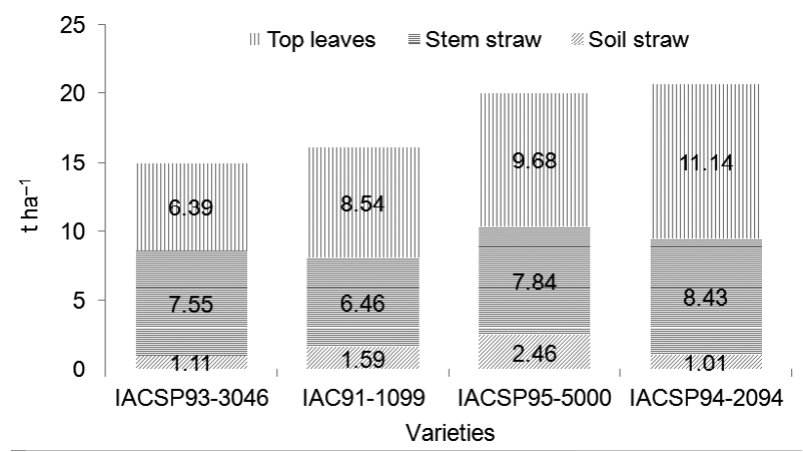

Figure 1 - Straw yield estimates in four sugarcane IAC varieties.

Table 3 - Dry mass content left on the soil after mechanized sugarcane harvesting. Manechini (1997).

\begin{tabular}{|c|c|c|c|c|c|}
\hline \multirow{2}{*}{ Vegetal material } & \multicolumn{5}{|c|}{ Cultivars } \\
\hline & SP80-185 & SP79-1011 & SP79-2233 & RB785148 & Average \\
\hline \multicolumn{6}{|l|}{$\mathrm{tha}^{-1}$} \\
\hline Dry leaves & 14.01 & 11.37 & 13.56 & 8.23 & 11.79 \\
\hline Green leaves & 1.34 & 1.93 & 1.25 & 1.73 & 1.56 \\
\hline Top leaves & 0.32 & 0.28 & 0.17 & 0.49 & 0.32 \\
\hline Total & 15.67 & 13.58 & 14.98 & 10.45 & 13.67 \\
\hline
\end{tabular}


results in high humidity at harvesting (approximately $79 \%)$. Thus, straw requires dehydration in the field to increase its capacity to generate thermal energy. As observed previously, in addition to the different volumes of biomass generated, it is important to consider that straw fiber content varies according to the sugarcane variety.

\section{Extracting stem composition}

Nine pre-commercial sugarcane materials were investigated, and the following characteristics among the materials were evaluated: average cellulose content of $50 \% \pm 4$; average hemicellulose content of $24 \% \pm 1$; and lignin content of $26 \% \pm 4$ (Table 8). Among these genotypes, IAC 122 had the lowest cellulose content $(44 \% \pm 3)$, and IAC 94 had the high-

Table 4 - Straw content of different cultivars.

\begin{tabular}{lc}
\hline Cultivars & \% straw \\
\hline IAC86-2210 & 14.1 \\
IAC87-3396 & 12.3 \\
IAC87-3413 & 13.8 \\
IAC91-2137 & 11.6 \\
IAC91-2195 & 9.3 \\
IAC91-2218 & 16.5 \\
IAC91-3143 & 15.1 \\
IAC91-3186 & 8.9 \\
IAC91-4216 & 11.3 \\
IAC91-5035 & 13.3 \\
IAC91-5155 & 9.1 \\
SP81-3250 & 19.2 \\
RB72454 & 13.6 \\
RB835486 & 11.4 \\
RB855536 & 12.8 \\
\hline
\end{tabular}

Table 5 - Straw content in different producing regions around the world.

\begin{tabular}{lcl}
\hline Authors & \% Residues & Location \\
\hline Niestrath & 20 & Louisiana, USA \\
Daubert & 10 & Louisiana, USA \\
Stewart & 10.6 & Louisiana, USA \\
Le Blanc & $5.2-7.4$ & Louisiana, USA \\
Keller & 15.43 & Louisiana, USA \\
Lopez Hernandez & 10 & Tucuman, Argentina \\
Payne \& Rhodes & 35 & Hawaii \\
Mayoral \& Vargas & $7-9.4$ & Porto Rico \\
Betancourt & 4.2 & Cuba \\
Deacon & 5 & Trinidad \\
Clayton \& Whittemore & 13 & Florida, USA \\
Fanjul & 7.5 & Louisiana, USA \\
Azzi & $2-4.5$ & São Paulo, Brazil \\
Humbert & $9-12.1$ & Mexico \\
Castro \& Balderi & 10.9 & Florida, USA \\
\hline Sources: Paes and Oliveira, & 2005 (adapted from: & Fernandes \& Oliveira, \\
1977). & &
\end{tabular}

est $(53 \% \pm 1)$. These results demonstrated that there is great genetic variation in the cellulose contents (approximately $10 \%$ ) of the materials, thus indicating a great genetic potential among these materials to obtain more productive commercial cultivars for 6 -carbon sugar production, such as lignocellulose compounds, which may be used to produce second-generation ethanol and in the development of other products by sugarcane mills.

According to Calmonovici (ETH BIOENERGY Director; personal communication) and Sheldon (2011), "green economy" or "bioeconomy" allows using these sugars as building blocks in an array of biochemical scopes to obtain products, such as "green" plastic, hydroxymethyl furfural, succinic acid, glutamic acid, glycerol, sorbitol, and farnesene, which can replace petrochemical use and generate biomass demand for this application.

Regarding 5-carbon sugars, hemicellulose contents ranged from $21 \% \pm 1$ for the IAC 122 genotype to 25 $\% \pm 1$ for the IAC 94 genotype (Table 8). Although the content variation in this sugar type was only $4 \%$ among the materials, it is possible to develop pentose-richer cultivars to produce 5-carbon materials for xylitol and furfural production or for special ethanol fermentations from these sugars. Reddy and Yang (2005) also found similar hemicellulose contents (19 to $24 \%$ ).

Genotypes that had a higher capacity to retain 6-carbon sugars (cellulose) also had a greater capacity to synthesize and store 5-carbon sugars (hemicellulose). However, this is not a standard, once genotypes IAC 87 and IAC 140 retained high cellulose contents $(50 \% \pm$ 0.2 vs. $52 \% \pm 0.4$, respectively) with identical concentration of hemicellulose $(23 \% \pm 0.8$ and 0.04 , respectively). Furthermore, IAC 114 and IAC 180 genotypes, which presented the lowest cellulose contents among the genotypes studied $(48 \% \pm 3$ and $45 \% \pm 4$, respec-

Table 6 - Total Stems per Hectare (TSH) and straw percentage prior to harvesting, in four sugarcane cultivars with distinct yield levels.

\begin{tabular}{|c|c|c|c|}
\hline Cultivars & TSH & $\begin{array}{l}\text { Straw content prior } \\
\text { to harvesting }\end{array}$ & Straw/TSH \\
\hline & \multicolumn{2}{|c|}{$\longrightarrow$ tha $^{-1} \longrightarrow$} & $\%$ \\
\hline \multirow{4}{*}{ LCP85-384 } & $104.4 \pm 2.9$ & $16.0 \pm 3.1$ & 15.4 \\
\hline & $84.8 \pm 2.9$ & $15.5 \pm 3.2$ & 18.2 \\
\hline & $66.4 \pm 7.2$ & $13.5 \pm 3.3$ & 20.3 \\
\hline & $32.0 \pm 4.7$ & $7.5 \pm 1.9$ & 23.4 \\
\hline \multirow{3}{*}{ CP65-357 } & $76.0 \pm 7.9$ & $13.3 \pm 4.7$ & 17.5 \\
\hline & $58.4 \pm 4.0$ & $10.6 \pm 2.9$ & 18.1 \\
\hline & $44.4 \pm 4.5$ & $8.5 \pm 2.9$ & 19.1 \\
\hline \multirow{4}{*}{ TUCCP77-42 } & $103.0 \pm 5.3$ & $12.5 \pm 1.3$ & 12.1 \\
\hline & $84.5 \pm 5.3$ & $10.9 \pm 1.5$ & 12.9 \\
\hline & $66.2 \pm 7.7$ & $8.9 \pm 1.6$ & 13.4 \\
\hline & $50.2 \pm 8.9$ & $6.9 \pm 1.9$ & 13.7 \\
\hline \multirow{3}{*}{ RA87-3 } & $71.9 \pm 4.1$ & $10.3 \pm 1.3$ & 14.3 \\
\hline & $65.3 \pm 4.7$ & $9.6 \pm 1.7$ & 14.7 \\
\hline & $59.4 \pm 4.4$ & $8.9 \pm 1.9$ & 15.0 \\
\hline
\end{tabular}

Source: Romero et al. (2007). 
Table 7 - Indexes for Top Leaves Dry Mass (TLDM)/Stem Mass (SM); Stem Straw Dry Mass (SSDM)/Stem Mass (SM); Soil Straw Dry Mass (SoSDM)/Stem Mass (SM); Total Mass of Sugarcane Dry Straw (TMSDS/Stem Mass (SM) and Top Leaves Dry Mass (TLDM)/Stem Straw Dry Mass (SSDM).

\begin{tabular}{lccccc}
\hline Varieties & \multicolumn{5}{c}{ Relation indexes } \\
\cline { 2 - 6 } & TLDM/SM & SSDM/SM & SoSDM/SM & TMSDS/SM & TLDM/SSDM \\
\hline IACSP93-3046 & 0.074 & 0.087 & 0.013 & 0.174 & 0.846 \\
IAC91-1099 & 0.094 & 0.071 & 0.017 & 0.182 & 1.322 \\
IACSP95-5000 & 0.116 & 0.094 & 0.029 & 0.239 & 1.234 \\
IACSP94-2094 & 0.121 & 0.091 & 0.011 & 0.223 & 1.322 \\
\hline Average & $0.101 \pm 0.014$ & $0.086 \pm 0.010$ & $0.018 \pm 0.008$ & $0.205 \pm 0.031$ & $1.181 \pm 0.227$ \\
\hline
\end{tabular}

Table 8 - Cellulose, hemicellulose and lignin contents in IAC precommercial sugarcane cultivars.

\begin{tabular}{lccc}
\hline Genetic Material & \multicolumn{3}{c}{ Fiber Components } \\
\hline IAC Identification & Cellulose & Hemicellulose & Lignin \\
\hline & & \multicolumn{3}{c}{$\%$} \\
IAC 81 & $53.32 \pm 0.91$ & $23.65 \pm 0.48$ & $23.04 \pm 0.80$ \\
IAC 87 & $50.18 \pm 0.19$ & $23.23 \pm 0.83$ & $26.58 \pm 0.32$ \\
IAC 94 & $53.47 \pm 1.27$ & $25.47 \pm 1.09$ & $21.06 \pm 0.43$ \\
IAC 114 & $47.87 \pm 3.2$ & $24.33 \pm 1.10$ & $27.83 \pm 0.34$ \\
IAC 122 & $43.83 \pm 2.67$ & $21.45 \pm 1.02$ & $34.72 \pm 0.64$ \\
IAC 140 & $51.91 \pm 0.36$ & $23.23 \pm 0.04$ & $24.86 \pm 0.14$ \\
IAC 143 & $53.20 \pm 21.7$ & $24.28 \pm 5.27$ & $22.52 \pm 7.89$ \\
IAC 171 & $53.37 \pm 2.62$ & $24.08 \pm 0.43$ & $22.55 \pm 0.29$ \\
IAC 180 & $45.38 \pm 4.2$ & $24.10 \pm 1.97$ & $30.52 \pm 2.30$ \\
\hline Average & $50.28 \pm 3.73$ & $23.76 \pm 1.10$ & $25.96 \pm 4.45$ \\
\hline
\end{tabular}

Preliminary results.

tively), were capable of synthesizing and retaining the highest hemicellulose contents (IAC $114=24 \% \pm 1$; and IAC $180=24 \% \pm 2$ ). Thus, the potential exists to develop cultivars that are rich in 6-carbon sugars and have low pentose contents.

Lignin contents ranged from $21 \% \pm 0.4$ to $35 \pm$ $0.6 \%$ in the IAC 94 and IAC 122 genotypes (Table 8), respectively. The data had a variation of almost $15 \%$ in lignin contents among the different genotypes. Reddy and Yang (2005) also found similar lignin results, which ranged from 23 to $32 \%$ in sugarcane. The relation of fiber contents in each genotype allows inferring that cellulose-rich genotypes are also lignin-poor. This information is very interesting for plant breeding because it allows developing cellulose-rich and ligninpoor materials, which is in line with their intended use in second-generation ethanol production. In obtaining cellulose-rich materials (6-carbon sugar ethanol source for ethanol production), it is possible to simultaneously obtain lignin-poor materials, which is a structural component of the lignocellulosic material that hinders the cellulose hydrolysis process, thereby increasing the costs of cellulose processing.

\section{Conclusions}

The production of sugarcane straw content varies according to cultivars. The greatest mass of sugarcane straw is in the top leaves, but stem straw accounts for more than $40 \%$ of the total straw in a sugarcane crop. The straw index could be used as a good tool to estimate the straw production in sugar crop, but these indexes should be obtained separately for each sugarcane variety to obtain more accurate forecasts of crop production. The potential for crude energy production of sugarcane can be increased using fiber-rich species or species that produce more straw, but the products of interest should be taken into account before choosing the crop variety. Finally, cellulose, hemicellulose and lignin composition in sugarcane is distinct among varieties, so it is possible to develop distinct materials for energy production and for the development of sugarcane mills using biochemical processes and thermal routes.

\section{Acknowledgement}

Research was supported by grants and fellowships from grant 2008/56146-5, São Paulo Research Foundation (FAPESP).

\section{References}

Bayer, C.; Mielniczuk, J.; Martin Neto, L.; Ernani, P.R. 2002. Stocks and humification degree of organic matter fractions as affected by no-tillage on a subtropical soil. Plant and soil 238: 133-140.

Fernandes, A.C., Oliveira, E.R. 1977. Sugar cane trash measurements in Brazil. In: International Society Of Sugar Cane Technologists Congress, São Paulo. Proceedings. São Paulo 978: 1963-1973.

Fernandes, A.C. 2003. Calculations in the Sugarcane Agroindustry = Cálculos na agroindústria da cana-de-açúcar 2ed. Brazilian Society of Sugarcane Technologists, Piracicaba, SP, Brazil (in Portuguese).

Francis, C.A.; Rutger, J.N.; Palmer, A.F.E. 1969. A rapid method for plant leaf area estimation in maize (Zea mays L.). Crop Science 9: 537-539.

Franco, H.C.J.; Pimenta, M.T.B.; Carvalho, J.L.N.; Magalhães, P.S.G.; Rossel, C.E.V.; Braunbeck, O.A.; Vitti, A.C.; Kolln, O.T; Rossi Neto, J. 2013. Assessment of sugarcane trash for agronomic and energy purposes in Brazil. Scientia Agricola 70: 345-352.

Gomes, E.O.; De Souza, R.T.G.; Rocha, G.J.M.; Almeida, E.; Cortez, L.A.B. 2010. Sugarcane trash as feedstock for second generation process. p. 637-659. In: Cortez, L.A.B., ed. Sugarcane bioetanol. Blucher, São Paulo, SP, Brazil. 
Manechini, C. 1997. Management of sugarcane. p. 309-327. In: Workshop of Agricultural Technologies, 7. Copersucar, Piracicaba, SP, Brazil.

Miocque, J. 1999. Evaluation of growth and yield of green matter of sugarcane from Araraquara, SP region. = Avaliação de crescimento e de produtividade de matéria verde da canade-açúcar na região de Araraquara-SP. STAB - Sugar, ethanol and byproducts = Açúcar, álcool e subprodutos 17: 45-47 (in Portuguese).

Paes, L.A.D.; Oliveira, M.A. 2005. Potential trash biomass of the sugar cane plant. p. 19-23. In: Hassuani, S.J.; Leal, M.R.L.V.; Macedo, I.C., ed. Biomass power generation: sugarcane, bagasse and trash. Piracicaba, SP, Brazil. Available at: www. sucre-ethique.org/IMG/pdf/CTC_energy_-_biomass_1_.pdf.

Reddy, N.; Yang, Y. 2005. Biofibers from agricultural by products for industrial applications. Trends in Biotechnology 23: 22-27.

Ripoli, M.L.C.; Franco, F.N.; Ripoli, T.C.C.; Gamero, A.C. 2005. The sugar cane crop residues unloaded in the sugar mill: operational costs and physical characteristics. Engenharia Rural 16: 17-23.
Romero, E.R.; Scandaliaris, J.; Digonzelli, P.; Alonso, L.; Leggio Neme, F.; Giardina, J.; Casen, S.; Tonatto y J.; Fernández De Ullivarri, J. 2007. Sugarcane potential trash estimation: variety and cane yield effect. Proceedings of the International Society of Sugar Cane Technologists 26: 421-425, Durban, South Africa.

Salton, J.C.; Mielniczuck, J.; Bayer, C.; Boeni, M.; Conceição, P.C.; Fabrício, A.C.; Macedo, M.C.M.; Broch, D.L. 2008. Soil aggregation and aggregate stability under crop-pasture systems in Mato Grosso do Sul state, Brazil. Revista Brasileira de Ciência do Solo 32: 11-21 (in Portuguese, with abstract in English).

Sheldon, R.A. 2011. Utilisation of biomass for sustainable fuels and chemicals: molecules, methods and metrics. Catalysis Today 167: 3-13. 